\title{
Modeling and experimental analysis of wheel-work interface in the cylindrical plunge grinding process
}

\author{
Tarik Tawfeek \\ ${ }^{1}$ Mechanical Engineering Department, Faculty of Engineering, Benha University, 108-Shoubra Street-Cairo- Egypt \\ E-mail:tariktewfic@yahoo.co.uk
}

Copyright $\odot 2014$ Tarik Tawfeek. This is an open access article distributed under the Creative Commons Attribution License, which permits unrestricted use, distribution, and reproduction in any medium, provided the original work is properly cited.

\begin{abstract}
This paper presents a study of grinding wheel-workpiece interference in external cylindrical plunge grinding processes. This is to study the effect of workpiece surface memory on the workpiece roundness error after grinding. The study has been carried out theoretically on a model simulating cylindrical grinding process. The model takes contact stiffness, grinding wheel and workpiece wear into consideration. The proposed model was sued to predict the normal grinding forces in cylindrical grinding as a function of the previous height and number of waves of the initial profile.

The new model has been validated by conducting experiments on a cylindrical grinding machine. Results indicate that the proposed model shows a good agreement with the experimental data obtained.

The results of experiments indicate that the proposed modeling method is both feasible and reliable. The results showed that the theoretical model was effective studying the output of cylindrical grinding process. Normal grinding force, vibration level, and roundness error in cylindrical plunge grinding processes are dependent on the workpiece surface memory
\end{abstract}

Keywords: Plunge Grinding, Modeling, Roundness Error, Surface Memory.

\section{Introduction}

There are many practical problems faced by engineers in a grinding process. This is due to the fact that the grinding process differs from many other processes in the complexity of the relationship between the machining parameters and the process performance. The process quality and productivity largely depend, not only on the manufacturing engineers experience and expertise but also on conventions regarding the phenomena that take place during processing. In the grinding process, many of these phenomena are highly complex and interact with a large number of factors, thus preventing high process performance. To overcome these problems, the researchers e.g. [1,2] propose models that try to simulate the conditions during grinding and establish cause and affect relationships between various factors and desired product characteristics.

Previous work on the modeling of a grinding process has concentrated on the possible approaches for optimizing grinding condition constraints during grinding for both the maximum workpiece removal and the best surface finish. Cai et al. [3] described the structure, content, and relations employed in an intelligent grinding database developed to provide selective and/or optimal data to the operator. Saravanan et al also [4] described a GA based optimization procedure to optimize grinding conditions (wheel speed, workpiece speed, depth of dressing, and lead of dressing) using a multi-objective function model with a weighted approach for surface grinding.

Out-of-roundness is a complex error resulting from grinding process. It refers to a deviation from a perfect circle. In a conventional plunge grinding operation, the grinding wheel is fed radially into a rotating workpiece by a wheel-head system. Since the wheel-head and the workpiece supports are not infinitely rigid, the deflection takes place as soon as the wheel contacts the workpiece and normal force is developed. This will result in grinding wheel position falling behind the nominal position of the wheel head system. Due to the variation in the deflection of the system during a grinding cycle, a relative motion (vibration) between workpiece and grinding wheel is initiated. Grinding efficiency and 
workpiece surface integrity are greatly affected by deflections that occur within the grinding contact zone. This will cause out-of -roundness on the ground workpiece surface.

Several models have been proposed in literature for the dynamic simulation of grinding, with the objective of representing of the effect of workpiece-wheel relative vibrations. A time-domain dynamic model, as presented in [5], simulates cylindrical plunge grinding processes under general grinding conditions. The model focuses on the prediction of grinding chatter boundaries and growth rates, taking into account several critical issues: the distributed nonlinear force along the contact length, the geometrical interaction between the wheel and workpiece based on their surface profiles, the structure dynamics with multiple degrees of freedom for both the wheel and workpiece, the response delay due to spindle nonlinearities and other effects, and the effect of the motion perpendicular to the normal direction. Besides the numerical approaches based on a workpiece-wheel discretization, pure analytical representation of process geometry and grinding forces have been used [6]. These analytical models are usually subject to strong assumptions that limit their generality: often they are used to gain insight into a particular phenomenon but the results are insufficient when trying to predict surface quality in real practical cases. The author showed how the onset of chaotic vibrations is possible under specific cutting condition. Leonesio et al [7], developed a simulation model for surface grinding, based on workpiece discretization by means of a z-buffer approach. The volume engaged by the wheel is associated to the grinding force by means of a variable specific energy that is a function of the equivalent chip thickness. The model is able to provide static and dynamic grinding force components. A grinding force and power model is developed in [8] for the reliable prediction of grinding force and power in ceramic grinding based on a new analytical undeformed chip thickness model. The model includes the real contact length that results from combined contact length, due to wheelworkpiece contact zone deflection and the local deflection resulting from the microscopic contact at the grain level and contact length due to geometry of depth of cut.

Most of works present in literature show complex force models validated on simplified machine dynamics. However, the investigations do not address the important issue concerned with the effect of the specimens surface memory on the resulted roundness error of the ground surface.

In this work, a model for a cylindrical grinding process has been developed based on workpiece surface memory. The study puts importance on the effect of previous workpiece profile on the normal grinding force that exists between the grinding wheel and the workpiece during grinding. The model has been validated by conducting experiments on a cylindrical grinding machine. The Root Mean Square (RMS) of vibration signals existing during grinding are used to describe this relative motion in the experimental investigation.

\section{Model description}

In the external cylindrical plunge grinding process, the wheel is fed radially into the workpiece. The cutting process takes place along the interference between the wheel and the workpiece via a number of abrasive grains on the wheel surface.

To study the effect of workpiece surface memory on the workpiece roundness error produced after grinding the cylindrical grinding process model which was derived by A. A. Ibrahim [9] will be used. The model takes contact stiffness, grinding wheel and workpiece wear into consideration.

The model takes the effect of the workpiece initial contour where number of waves on the workpiece surface is $n$, and an amplitude $a_{n}$ as shown in figure 1. Figure 2 shows the influences of previous waviness on the dynamic normal force [10]. The component of the grinding force $F_{n g}$ appears when over grinding a smooth workpiece surface, a component $\mathrm{F}_{\mathrm{nw}}$ which from real wavy surface and the resultant dynamic normal grinding force $\mathrm{F}_{\mathrm{n}}$.

That is,

$\mathrm{U}(\mathrm{t})+\mathrm{a}_{\mathrm{n}} \cos \mathrm{n} \omega \mathrm{t}=\mathrm{W}_{\mathrm{w}}(\mathrm{t})+\mathrm{W}_{\mathrm{g}}(\mathrm{t})+\mathrm{X}_{\mathrm{cm}}(\mathrm{t})$

Where

$\mathrm{U}(\mathrm{t})$ : is the total infeed of the grinding wheel

$\mathrm{W}_{\mathrm{w}}(\mathrm{t})$ : is the total amount of the workpiece wear,

$\mathrm{W}_{\mathrm{g}}(\mathrm{t})$ : is the total amount of the grinding wheel wear,

$\mathrm{X}_{\mathrm{cm}}(\mathrm{t})$ : is the total elastic deformation at contact area and elastic deformation of machine tool structure.

The term $a_{n} \cos n \omega t$ which was added to the total infeed in the right side of the equation (1) is due to the effect of the dynamic normal grinding force $\mathrm{F}_{\mathrm{n}}$ which is a periodic force.

The work wear was related to the interface grinding force as a pure time delay element by the following equation in Laplace domain

$W_{w}=\frac{F_{n}}{K_{w}\left(1+e^{-\tau_{w} S}\right)}$

Where:

$\mathrm{F}_{\mathrm{n}}$ : is the dynamic normal grinding force

$\mathrm{K}_{\mathrm{w}}$ : is the wear stiffness of work piece, and

$\tau_{w}:$ is the pure time delay due to workpiece wearing $=1 / \mathrm{N}_{\mathrm{w}}$ 
The total amount of the grinding wheel wear and the interacting grinding force can be related in the Laplace domain as $W_{g}=\frac{F_{n}}{K_{g}\left(1+e^{-\tau_{g} S}\right)}$

Where:

$\mathrm{K}_{\mathrm{g}}$ : is the wear stiffness of grinding wheel, and

$\tau_{g}:$ is the pure time delay due to wheel wearing $=1 / \mathrm{N}_{\mathrm{g}}$

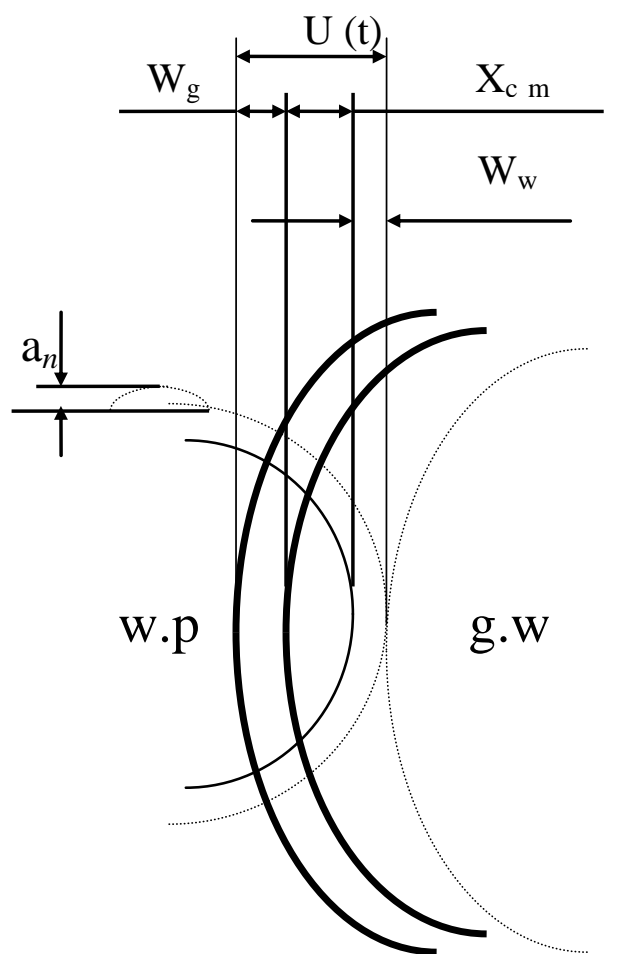

Fig. 1: The Total Infeed of the Grinding Wheel at the Time Instant $T$ [9]

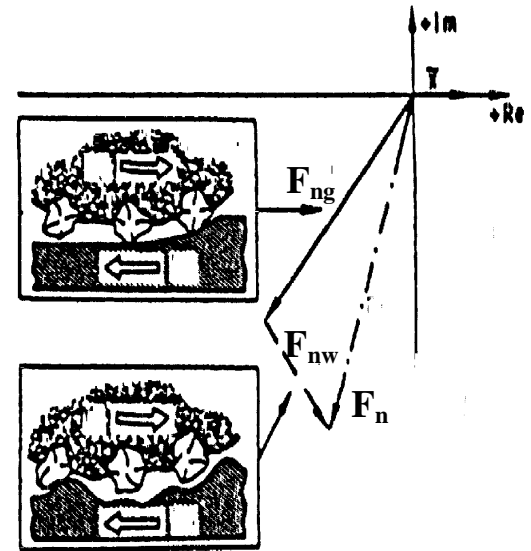

Fig. 2: The Effect of Initial Waviness on Dynamic Normal Force [10].

The elastic deformations $X_{c m}$ is dependent on the grinding force $F_{n}$, workpiece geometry, and machine stiffness, especially head and tail stock. This can be modeled to represent a machine with rigid head and tail stoke, then:

$X_{c m}=\frac{F_{n}(L-x)^{2} x^{2}}{3 E L I}$

Where

$\mathrm{L}$ : is the workpiece length

$\mathrm{E}$ : is the modulus elasticity

$\mathrm{I}$ : is the second moment of area

$\mathrm{X}$ : is the distance from headstock to the center of grinding wheel

The sum of system infeed in $\mathrm{mm} / \mathrm{rev}$ can be written as

$\mathrm{U}(\mathrm{t})-\mathrm{a}_{\mathrm{n}} \mathrm{n} \omega \sin \mathrm{n} \omega \mathrm{t}=\mathrm{W}^{\cdot}{ }_{\mathrm{w}}(\mathrm{t})+\mathrm{W}^{\cdot}{ }_{\mathrm{g}}(\mathrm{t})+\mathrm{X}^{\cdot}{ }_{\mathrm{cm}}$

Systems that are described inherently by transcendental pure time delay transfer functions are more difficult to handle, hence, there are many ways of approximating pure time delay function via a rational function. One way is to approximate the exponential function by a Maclaurin series. A better approximation is to use the Pade approximation, which is given in the following, for a two-term approximation of workpiece wearing and grinding wheel wearing with pure time delay as;

$e^{-\tau_{w} S}=\frac{1-\tau_{w} / 2 S}{1+\tau_{w} / 2 S}$

And

$e^{-\tau_{g} S}=\frac{1-\tau_{g} / 2 S}{1+\tau_{g} / 2 S}$

The approximation of the transfer functions contains a zero in the right-half .y-plane so that the step response of the approximating system may exhibit a small negative undershoot near $\mathrm{t}=0$.

The wheel stiffness can be related to the wheel width $\mathrm{W}$ and the wheel wear parameter $\mathrm{A}_{\mathrm{w}}$ and wheel wear parameter $\mathrm{A}_{\mathrm{g}}$ as; 


$$
K_{w}=\frac{V_{w} \cdot W}{A_{w}}
$$

And

$$
K_{g}=\frac{V_{g} W}{A_{g}}
$$

Because the wear of the grinding wheel is far smaller than that of the workpiece, it can be neglected for this study.

Since the vibration of the grinding wheel relative to workpiece depends on the depth of cut (infeed in cylindrical plunge grinding mode), the dynamic displacement which adds to the total infeed in eq. (1) will cause the grinding wheel to move away from or toward the workpiece according to the displacement sign. Then relative vibration occurs between the workpiece and grinding wheel which causes new waves to be produced on the workpiece surface.

A group of parametric analysis was done to illustrate the effect of previous surface memory such as previous wave's amplitude and the number of waves on the surface prior to grinding on the normal grinding forcer who will affect the stability analysis of the grinding system. The above mentioned equations of the workpiece-grinding wheel interface were used to build a simulink model for the system (figure 3).

The followings are the system input parameters to the model:

- The workpiece material is steel and the length is $100 \mathrm{~mm}$ while the workpiece diameter is $50 \mathrm{~mm}$

- Wheel speed $\left(\mathrm{n}_{\mathrm{g}}\right)=1600$ r.p.m.

- $\quad$ Amplitude of previous waves $\left(\mathrm{a}_{\mathrm{n}}\right)=5.5,7.6$, and $9.6 \mu \mathrm{m}$

- $\quad$ No. of wave on workpiece surface prior grinding $(\mathrm{n})=3,4$, and 7 waves.

- $\quad$ Infeed (f) $=0.01 \mathrm{~mm} / \mathrm{rev}$.

- Grinding wheel width ( width of cut) $=20 \mathrm{~mm}$

- $\quad$ Workpiece speed $\left(\mathrm{n}_{\mathrm{w}}\right)=130$ r.p.m

\subsection{Model output}

The model output is the normal grinding force which is a periodic force. It the most effective force on the roundness error because the vibration existing between the wheel and workpiece is dependent on this force.

A trial run for the model was conducted (shown in figure 4) to observe the time at which the normal force reach the steady state value. In this figure the normal grinding force is plotted versus time for different wave s' amplitudes. The number of waves (n) was 3 for the data plotted in figure $4 \mathrm{a}$, while it was 4 for the data plotted figure $4 \mathrm{~b}$. The minus sign of the force indicates the force is a compressive force. The figure shows the normal force became steady after 5 second, for this reason, the value of the force will be monitored at a time of $5 \mathrm{sec}$. and will be used in studying other relations. It can also be seen from the figure that the normal force is dependent on the wave's amplitudes of the previous surface.

Figure 5 shows that the normal grinding force is dependent on the number of waves on the previous surface and their amplitudes. As seen in figures 4 , and 5 the normal grinding force increases as waves amplitude increase. It can be seen also from figures 4 , and 5 that, the normal force was high when the initial profile has a low number of waves ( $\mathrm{n}=3$ waves) and that the force decreases as the number of waves increases. This result matched with the result obtained by Liao et al. [11] which reported that, increasing the number of waves (n) on the workpiece circumference is an alternative to improving its roundness. 


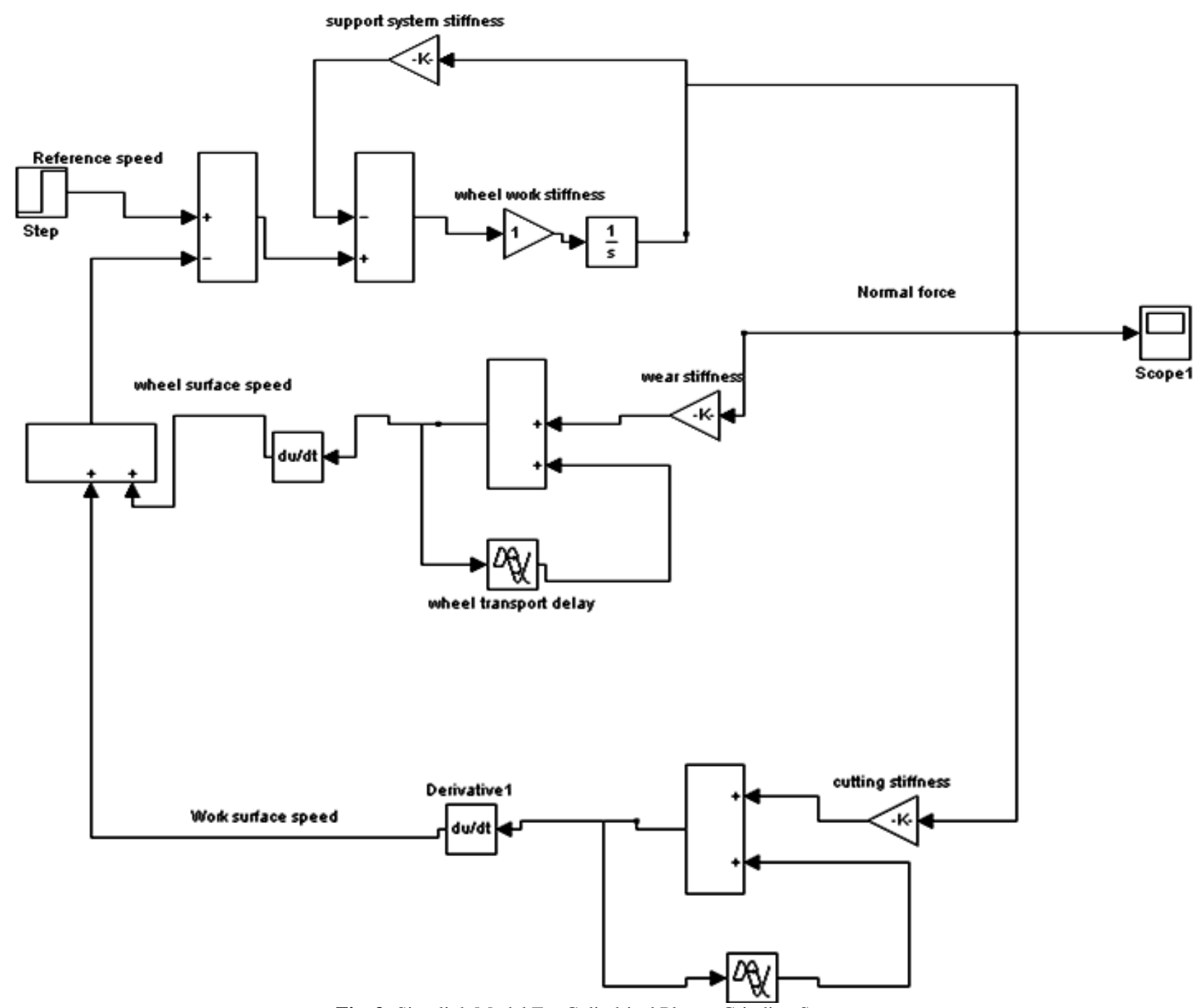

Fig. 3: Simulink Model For Cylindrical Plunge Grinding System

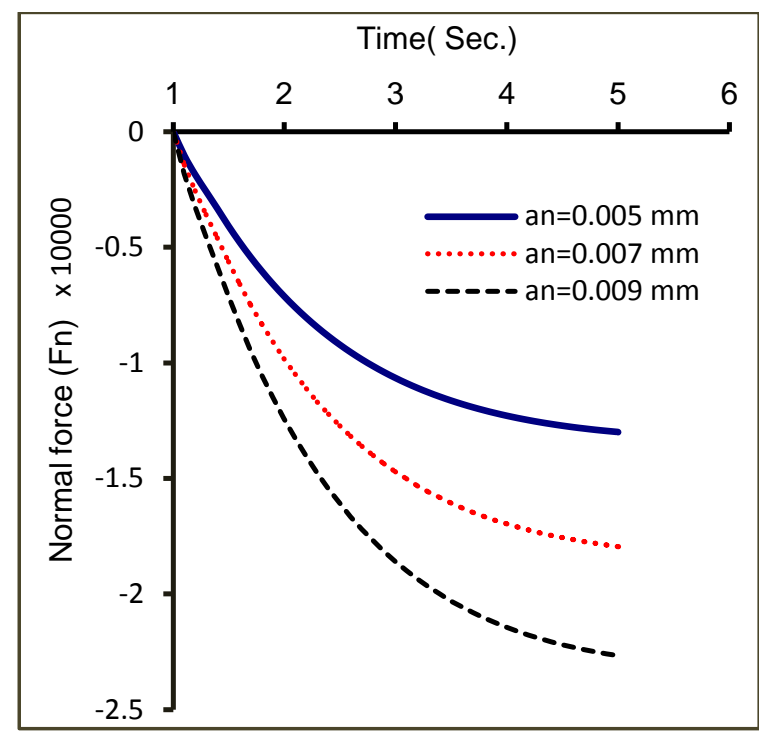

A) $\mathbf{N}=\mathbf{3}$

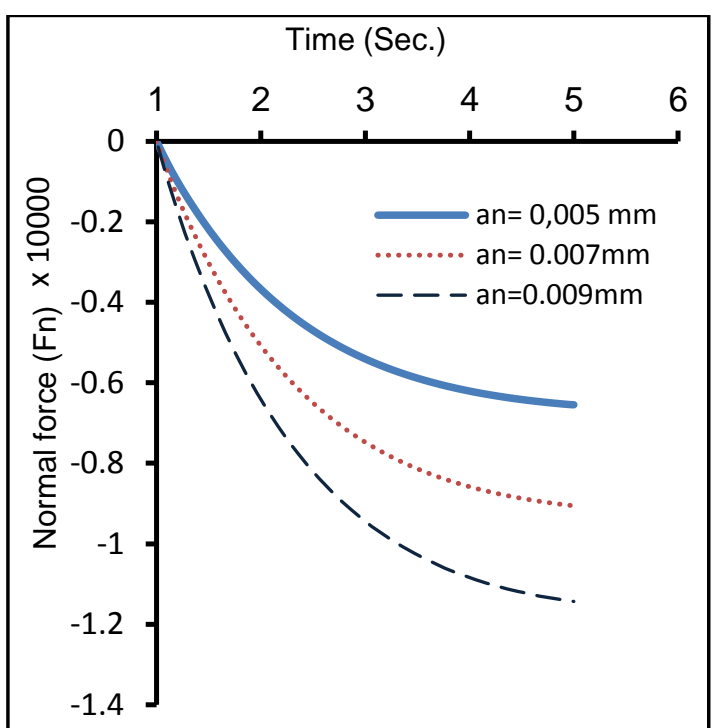

B) $\mathbf{N}=4$

Fig. 4: Effect of Work piece Previous Waves Amplitude on the Normal Grinding Forced at, $\mathrm{N}=130 \mathrm{Rpm}$, and $\mathrm{F}=0.01 \mathrm{Mm} / \mathrm{Srev}$. 


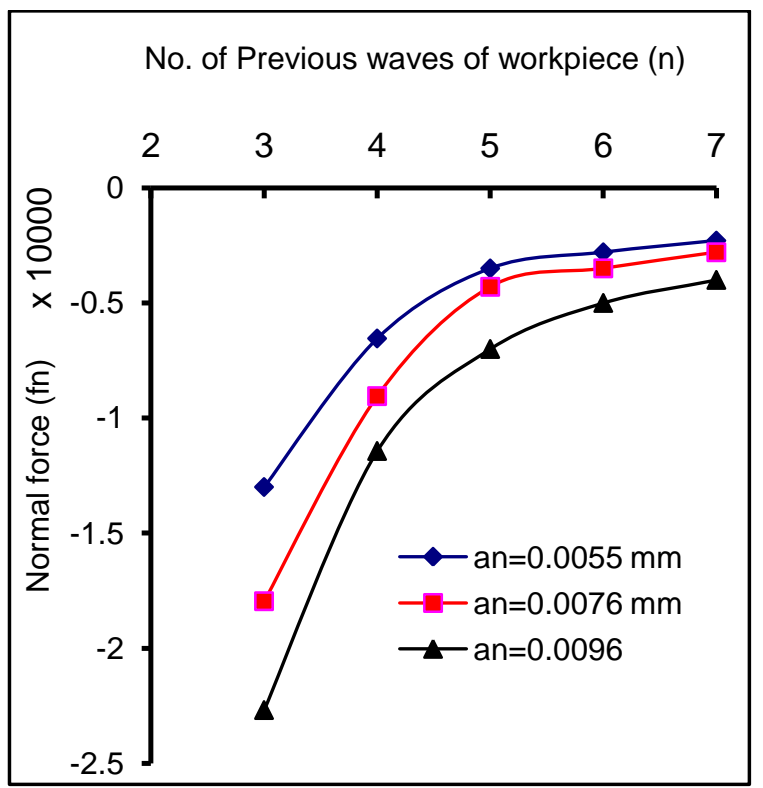

Fig. 5: Variation of Normal Force Versus Number of Previous Waves on Work piece At N=130 Rpm and F=0.01 Mm/Rev.

\section{Experimental campaign}

The experimental campaign for model parameters identification and validation was conducted on a cylindrical grinding machine (Jones \& shipman model 1300) to study the effect of initial workpiece surface memory on the surfaces produced by grinding process.

First a turning operation was carried out using different conditions to produce specimens from a rolled steel bar of $50 \mathrm{~mm}$ diameter. The composition of this steel is $0.48 \% \mathrm{C}, 0.25 \% \mathrm{Si}, 0.8 \% \mathrm{Mn}$ and $0.018 \% \mathrm{~S}$. The-out-of roundness of the machined specimens was measured before and after grinding.

A plunge cut grinding test was conducted on four of the turned specimens. These specimens were chosen to ensure that they had different out of roundness and number of waves.

The grinding wheel used for the test was A60KV7 with $400 \mathrm{~mm}$ outside diameter, $127 \mathrm{~mm}$ bore and $25 \mathrm{~mm}$ thickness. The dressing operation was applied to the wheel before grinding each specimen with $20 \mu \mathrm{m}$ depth of dresser and $0.125 \mathrm{~mm} / \mathrm{rev}$. feed rate, with four passes.

The grinding conditions were constant for all specimens as follow:

Wheel speed $\left(\mathrm{n}_{\mathrm{g}}\right)$ : 1600 r.p.m.

workpiece speed $\left(\mathrm{n}_{\mathrm{w}}\right): 140$ r.p.m.

Infeed (f): $0.025 \mathrm{~mm} / \mathrm{rev}$.

Width of grinding: $20 \mathrm{~mm}$

The specimens were mounted between two centers and each workpiece was machined for a limited time of 5 Sec only to avoid born in chatter.

The variation of the actual interference between the workpiece and the grinding wheel surface was monitored by means of vibration. The portable vibration analyzer B \& K 2515 was used to measure the vibration signals that existed during grinding. Because of the workpiece form errors determined by the relative displacements of the grinding wheel in direction normal to the ground surface, the vibration accelerometer was fixed on a horizontal plan on the workpiece head. The vibration was monitored through the analyzer in frequency domain and the root mean square (RMS) in acceleration of the signal for each workpiece was recorded. The RMS of vibration was used as indication for the value of normal grinding force. The (RMS) values recorded during grinding are given in table (1).

Table 1: Results of Experiments

\begin{tabular}{|l|l|l|l|l|l|}
\hline \multicolumn{2}{|l|}{ Workpiece } & 1 & 2 & 3 & 4 \\
\hline RMS $\left(\mathrm{m} / \mathrm{sec}^{2}\right)$ & 2.195 & 2.360 & 2.961 & 3.761 \\
\hline \multirow{2}{*}{ Out of roundness $(\mathrm{O}) \mu \mathrm{m}$} & Before grinding & 5.5 & 6.5 & 7.6 & 9.6 \\
\cline { 2 - 7 } & After grinding & 3.8 & 5 & 5.7 & 7.2 \\
\hline Undulation number & 7 & 6 & 4 & 3 \\
\hline
\end{tabular}

Measurement of out-of-roundness was carried out for each workpiece after it had been ground on a precision roundness measurement instrument (Talyround 250). The measured values of out of roundness for the each specimen before and after grinding are shown in table 1. 
As is known, out of roundness is a complex periodic error which can be resolved by Fourier's sinusoidal harmonics. The amplitude spectra of roundness profile are calculated for all workpiece and plotted for different harmonics as shown in figure 6 . The undulation number, which indicates the number of waves on the workpiece profile before grinding, was calculated for each specimen and given in table 1.

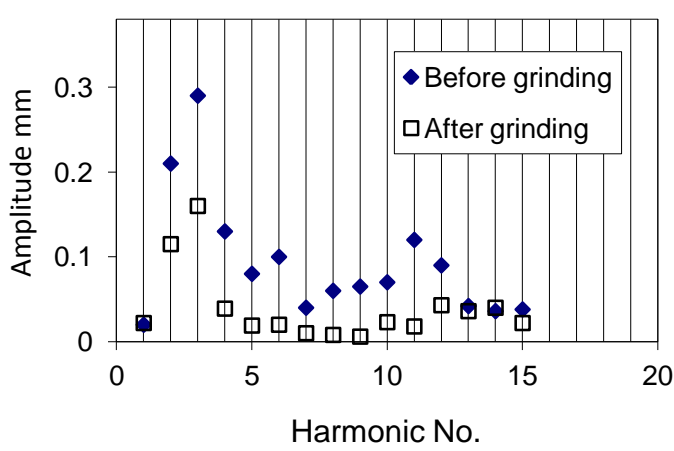

Workpiece No. 1

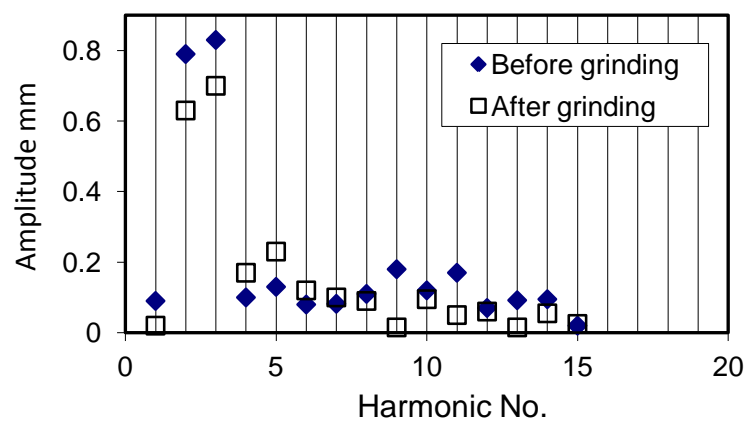

Workpiece No. 3

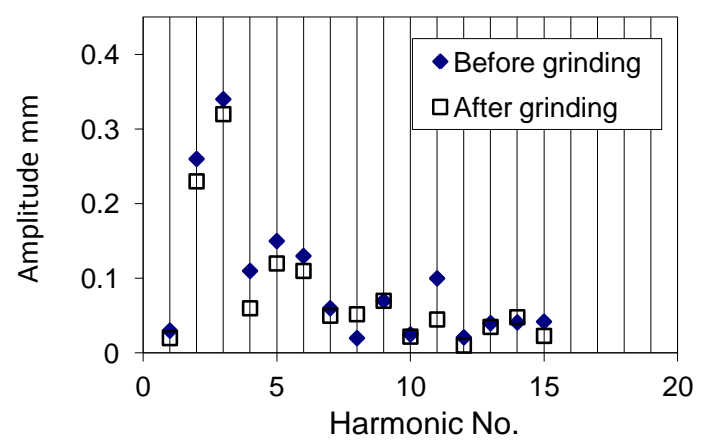

Workpiece No. 2

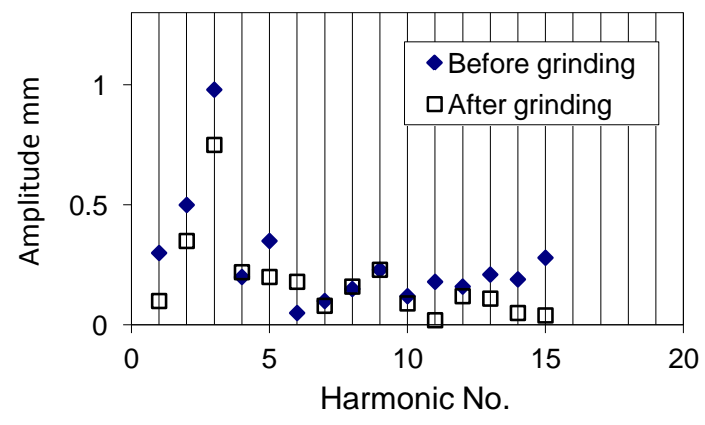

Workpiece No. 4

Fig. 6: Roundness Spectrum Workpieces before and after Grinding

\subsection{Discussion of experimental results}

The tests results given in Table 1 show the roundness error for the workpieces before and after grinding. It can be seen that the roundness error (out-of-roundness (0)) of the workpiece resulting from grinding and RMS of vibration level that is recorded during the operation are dependent on the initial workpiece roundness error. This can be described by the fact that the initial roundness error affects the dynamics of the system and works as an exciter for this system. This resulted in increasing RMS of vibration which denotes that the amplitude of normal grinding force was increased. The increase of vibration level (i.e. wheel-workpiece relative motion) caused the roundness error on the new profile.

The effect of the initial workpiece profile on the final profile which resulted from grinding is obvious when the amplitude spectra are considered as a parameter for roundness measurement as shown in figure 6 . It can be noted from the figure that the dominant harmonics before grinding are almost the same after grinding. The amplitudes at different harmonics also depend on their values before grinding process. The results shown in table 1 also show that, The number of waves on the workpiece initial profile have a great effect on RMS of vibration level and out-of-roundness after grinding.

The results of these experiments coincide with those obtained from the proposed grinding model. When the number of waves on the initial surface increased RMS of vibration decreased and consequently the out-of-roundness was reduced. The experimental results show that the proposed grinding model for dynamic simulation for the cylindrical grinding process is able to predict the average level of the normal grinding force as well as the effect of workpiece surface memory on the profile that resulted from cylindrical grinding process.

\section{Conclusions}

In this paper, a grinding force model for dynamic simulation for cylindrical grinding process has been derived and verified experimentally. The proposed model is able to predict the average level of the normal grinding force as well as the effect of workpiece initial profile on the profile that resulted from the grinding process.

The major contributions of this work include: 
1) The initial workpiece profile has a considerable effect on the process as it disturbs the process and changes the wheel-workpiece dynamic interference.

2) The RMS of vibration signal that exists during the process depends on the initial specimen roundness error.

3) The roundness error of the ground workpiece depends on the roundness error and undulation number of the workpiece before grinding.

The effect of the initial workpiece profile on the ground one is obvious with the amplitude spectra of the profiles. The amplitude at different harmonics is corresponding to that before grinding.

\section{References}

[1] T.A. Nguyen, D.L. Butler Simulation of precision grinding process, part 1: generation of the grinding wheel surface", International Journal of Machine Tools \& Manufacture 45(2005) 1321-1328 http://dx.doi.org/10.1016/j.ijmachtools.2005.01.005.

[2] T.A. Nguyen, D.L. Butler, Simulation of surface grinding process, part 2: interaction of the abrasive grain with the workpiece", International Journal of Machine Tools \& Manufacture 45 (2005) 1329-1336 http://dx.doi.org/10.1016/j.ijmachtools.2005.01.006.

[3] R. Cai \&W. B. Rowe \& J. L. Moruzzi \& M. N. Morgan Intelligent grinding assistant (IGA) - system development part I intelligent grinding database", Int J Adv Manuf Technol 35 (2007) 75-85 http://dx.doi.org/10.1007/s00170-006-0702-4.

[4] R. Saravanan, P. Asokan, M. Sachidanandam A multi-objective genetic algorithm (GA) approach for optimization of surface grinding operations", International Journal of Machine Tools \& Manufacture 42 (2002) 1327-1334 http://dx.doi.org/10.1016/S0890-6955(02)00074-3 .

[5] Hongqi Li., Shin Y.C., A Time-Domain Dynamic Model for Chatter Prediction of Cylindrical Plunge Grinding, Journal of Manufacturing Science and Engineering, 128 (2006), 404-415. http://dx.doi.org/10.1115/1.2118748.

[6] Stanescu N.D., Chaos in Grinding Process, transactions on applied and theoretical mechanics, 4 (2009) (4).

[7] Marco Leonesioa, Paolo Parentib, Alberto Cassinaria, Giacomo Bianchia, Michele Monnob, A Time-Domain Surface Grinding Model for Dynamic Simulation, Procedia CIRP 4 (2012) 166 - 171. http://dx.doi.org/10.1016/j.procir.2012.10.030.

[8] Sanjay Agarwal, P. Venkateswara Rao, Predictive modeling of force and power based on a new analytical undeformed chip thickness model in ceramic grinding, International Journal of Machine Tools \& Manufacture 65 (2013) 68-78 http://dx.doi.org/10.1016/j.ijmachtools.2012.10.006.

[9] A.A. Ibrahim, Improving roundness error in the cylindrical plunge grinding using ai technique" Engineering Research Journal of EL-Mataria faculty of Eng., Helwan University, Cairo, Egypt.117 (2008) M 124-M142.

[10] K. Steffens and H. Follinger, A new approach for investiging dynamic effects in grinding" Annals of CIRP 34 (1985) 267. http://dx.doi.org/10.1016/S0007-8506 (07)61770-3.

[11] Y.S.Liao, and L.C.shiang, Computer simulation of self - excited and forced vibrations in the external plunge grinding process" Journal of Engineering for industry 113(1991) 297-304 http://dx.doi.org/10.1115/1.2899700.

\section{Future work}

Future investigation will be conducted aiming to improve the capability of the model to predict instability occurrence due to initial workpiece. Further developments will regard the integration of stochastic features in the force model, aiming at taking into account grits-workpiece interaction.

\section{Nomenclature}

$a_{n:}$ the wave amplitude.

$\mathrm{k}_{\mathrm{g}}, \mathrm{k}_{\mathrm{w}}$ : the grinding wheel and workpiece wear stiffness respectively.

$\mathrm{N}$ : number of waves on workpiece initial profile.

$\mathrm{U}(\mathrm{t})$ : total infeed of the grinding wheel at the time instant $\mathrm{t}$.

$\mathrm{W}_{\mathrm{w}}(\mathrm{t})$ : instantaneous amount of wear of the workpiece.

$\mathrm{W}_{\mathrm{g}}(\mathrm{t})$ : instantaneous amount of wear of the grinding wheel.

$\mathrm{X}_{\mathrm{cm}}(\mathrm{t})$ : is the total elastic deformation at contact area and elastic deformation of machine tool structure.

$\mathrm{F}_{\mathrm{n}}$ : the dynamic normal grinding force

$\mathrm{K}_{\mathrm{w}}$ : the wear stiffness of work piece, and

$\tau_{w}:$ The pure time delay due to workpiece wearing $=1 / \mathrm{N}_{\mathrm{w}}$

$\mathrm{K}_{\mathrm{g}}$ : the wear stiffness of grinding wheel, and

$\tau_{g}:$ The pure time delay due to wheel wearing $=1 / \mathrm{N}_{\mathrm{g}}$

L: the workpiece length

E: the modulus elasticity

I: the second moment of area

$\mathrm{X}$ : the distance from headstock to the center of grinding wheel

$\mathrm{n}_{\mathrm{g}}$ : wheel speed

$\mathrm{a}_{\mathrm{n}}$ : Amplitude of previous waves

$\mathrm{f}$ : Infeed $\mathrm{mm} / \mathrm{rev}$. 